\title{
Analysis of the antibacterial properties of polycaprolactone modified with graphene, bioglass and zinc-doped bioglass
}

\author{
MACIEJ B. HAJdUGA ${ }^{1 *}$, RAFAŁ BobIŃSKI ${ }^{1}$, MIECZYSŁaW DUTKA ${ }^{1}$, IZABELA UlMAN-WŁODARZ ${ }^{1}$, JAN BuJOK ${ }^{1}$,

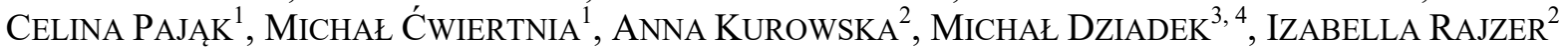 \\ ${ }^{1}$ Faculty of Health Sciences, ATH University of Bielsko-Biala, Bielsko-Biała, Poland. \\ ${ }^{2}$ Department of Mechanical Engineering Fundamentals, ATH University of Bielsko-Biala, Bielsko-Biała, Poland. \\ ${ }^{3}$ Department of Glass Technology and Amorphous Coatings, Faculty of Materials Science and Ceramics, \\ AGH University of Science and Technology, Kraków, Poland. \\ ${ }^{4}$ Faculty of Chemistry, Jagiellonian University, 30-387 Kraków, Poland.
}

\begin{abstract}
Purpose: Innovative biomedical filaments for 3D printing in the form of short and biodegradable composite sticks modified with various additives were used to prepare biomaterials for further nasal implants. As the respiratory tract is considered to be potentially exposed to contamination during the implantation procedure there is a need to modify the implant with an antibacterial additives. The purpose of this work was to analyze the effect of biodegradable polymer - polycaprolactone (PCL) modification with various additives on its antibacterial properties. Methods: PCL filament modified with graphene $(0.5,5,10 \% \mathrm{wt}$.$) , bioglass (0.4 \% \mathrm{wt}$.$) and zinc-doped bioglass (0.4 \% \mathrm{wt}$.$) were$ used to print spatial biomaterials using FDM 3D printer. Pure polymer biomaterials without additives were used as reference samples. The key task was to assess the antimicrobial impact of the prepared biomaterials against the following microorganisms: Staphylococcus aureus ATCC 25293, Escherichia coli ATCC 25922, Candida albicans ATCC 10231. Results: The research results point to a significant antibacterial efficacy of the tested materials against $S$. aureus and C. albicans, which, however, seems to decrease with increasing graphene content in the filaments. A complete lack of antibacterial efficacy against E. coli was determined. Conclusions: The tested biomaterials have important antibacterial properties, especially against $C$. albicans. The obtained results showed that biomaterials made of modified filaments can be successfully used in implantology, where a need to create temporary tissue scaffolds occurs.
\end{abstract}

Key words: polycaprolactone, graphene, bioglass, antibacterial, zinc

\section{Abbreviations}

PCL - polycaprolactone

FDA - Food and Drug Administration

GNP - graphene nanopellets

FDM technology, Fused Deposition Modelling

CFU - colony forming unit

ABE - antibacterial efficacy

AFE - antifungal efficacy.

\section{Introduction}

The use of biomaterials is currently an important element of modern medicine. It complements surgical treatment [13] and often pharmacological treatment, too [7]. The biomaterials themselves do not have a pharmacological effect, only their additives. Polycaprolactone (PCL) has gained much attention as one of the materials used in medicine for the production of biodegradable implants due to its high flexibility and biodegradability (2-4 years), as well as hydrophobicity [26]. Polymers can be successfully used as intracranial implants and carriers of therapeutic substances and drugs [24]. Multifunctional polymers with antibacterial properties can also be used in drug delivery systems [21]. It has been also approved by the Food and Drug Administration (FDA). PCL is a semi-crystalline polymer and some authors report that an increase in molecular weight causes a decrease in its crystallinity

\footnotetext{
* Corresponding author: Maciej B. Hajduga, Faculty of Health Sciences, ATH University of Bielsko-Biala, ul. Willowa 2, 43-300 Bielsko-Biała, Poland. Phone: +48 338279403, e-mail: mbhajduga@ath.bielsko.pl

Received: December 3rd, 2020

Accepted for publication: April 16th, 2021
} 
[25]. Compared to other polymers, PCL has many advantages such as biodegradability, biocompatibility, good mechanical strength and it can be also easily shaped. PCL is also resistant to electromagnetic fields [23]. However, these properties may not be sufficient in specific medical cases.

An essential and important feature of implants used in laryngology, for example, is their bacteriostatic or even bactericidal properties [10]. It is often impossible to obtain perfect asepsis during a surgery inside nasal cavities [12]. In order to achieve this, the implant material can be modified by enriching it with medications or substances with bacteriostatic or bactericidal properties.

One of the recognized materials with such properties is graphene and its derivatives [9], [16]. Graphene exhibits antibacterial action by direct contact of its sharp edges with membranes of microbial cells, which causes destructive extraction of lipid particles from their inside [1], [11]. In addition, graphene is used as a carrier for various types of metallic nanomaterials, metal oxides and polymers. Due to their excellent antibacterial properties [29] and good biocompatibility, graphene-based nanocomposites have a wide range of applications, such as antibacterial packaging, wound dressings and water disinfection.

Bioglass is another substance with antibacterial properties [8]. It is used as a top layer for the base material [22]. It can be also used as an additive during its production process [5]. Its confirmed antibacterial efficacy against $S$. aureus [18] is desirable when there is an increased risk of perioperative infection with this microorganism.

Zinc is a well-known element with significant bactericidal properties. It is mainly used in the form of oxides. It is used successfully in combination with polymers, including polycaprolactone [3], and with graphene [28].

In this paper a comparative analysis of the bactericidal properties of polycaprolactone filaments with the addition of graphene, bioglass and zinc-doped bioglass is presented. Materials for research were produced using the 3D printing technique.

\section{Materials and methods}

\subsection{Filaments preparation}

This research employed polycaprolactone in granular form, (PCL, Mn $80 \mathrm{kDa}$, Sigma Aldrich), bioactive glass
(BG) with the composition (mol \%): $40 \mathrm{SiO}_{2}-54 \mathrm{CaO}-$ $-6 \mathrm{P}_{2} \mathrm{O}_{5}$ (produced with the sol-gel method, AGH, Poland), bioactive glass doped with zinc $\mathrm{BGZn}$ with the composition (mol \%): $49 \mathrm{CaO}-5 \mathrm{ZnO}-6 \mathrm{P}_{2} \mathrm{O}_{5}-40 \mathrm{SiO}_{2}$ (prepared by the sol-gel method, AGH, Poland) [4], [20]. Flake graphene in powder form (GNP) was also used to modify the filaments (Sigma Aldrich, USA). The properties of the PCL used in the study are presented in Table 1.

Table 1. Properties of the PCL used in the study (Sigma-Aldrich)

\begin{tabular}{|l|l|}
\hline form & pellets $(\sim 3 \mathrm{~mm})$ \\
\hline mol wt & average $M_{n} 80,000$ \\
\hline impurities & $<0.5 \%$ water \\
\hline $\mathrm{mp}$ & $60{ }^{\circ} \mathrm{C}$ (lit.) \\
\hline density & $1.145 \mathrm{~g} / \mathrm{mL}$ at $25^{\circ} \mathrm{C}$ \\
\hline$M_{w} / M_{n}$ & $<2$ \\
\hline
\end{tabular}

In order to produce filaments for 3D printing, polymer mixtures with additives and pure PCL granulate were prepared. The polymer granules were dry mixed with GNP powder to obtain $0.5,5$ and $10 \%$ by weight of graphene content in the mixture. The content of bioglass and zinc-doped bioglass was $0.4 \%$ by weight. After combining the ingredients, each of the mixtures was mixed in a mechanical mixer for 20 minutes. Filaments in the form of modified sticks were manufactured in the process of injection moulding using a BabyPlast 6/10P (Rambaldi Group) injection moulding machine. The parameters of filament production were described in [19].

For the production of biomaterials in the form of a truss, a 3D printer (Anet A8), working in FDM technology, was used. Filaments in the form of sticks with a length of $50 \mathrm{~mm}$ and a diameter of $1.75 \mathrm{~mm}$ were used, having been joined together. Samples measuring $10 \times 20 \times 2 \mathrm{~mm}$ were printed (Figs. 1, 2). The temperature of the printer nozzle was $170-190{ }^{\circ} \mathrm{C}$ for individual filaments. The material was extruded through a nozzle, forming a $0.2 \mathrm{~mm}$ thick path. The scaffolds were printed at a speed of $15 \mathrm{~mm} / \mathrm{s}$. 12 samples of each type were made, yielding a total of 72 samples. Microscopic observations of the prepared biomaterials were carried out using the OPTA-TECH optical microscope equipped with a CMOS 3 camera and OptaViewIS software. Digital microscope Keyence VHX-6000 was used to analyse the surface profile of tested samples (Figs. 3, 4). All the samples were plasma-sterilised. As can be seen in Figs. 1 and 2, all scaffolds possessed the pore size large enough to promote further ingrowth of tissue and to facilitate better fixation of the future implant by surgeons. 


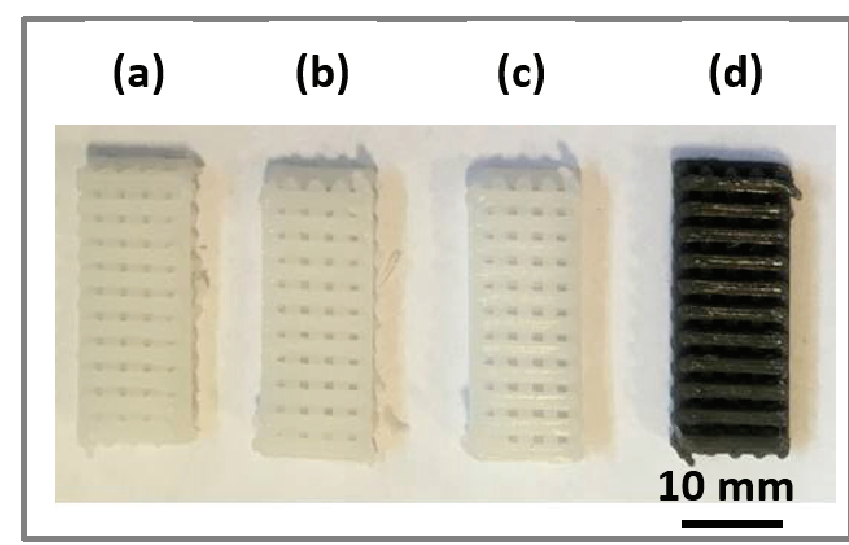

Fig. 1. Macroscopic images of prepared biomaterials: (a) PCL, (b) PCL_BG, (c) PCL_BG_Zn, (D) PCL_Graf_0.5\%
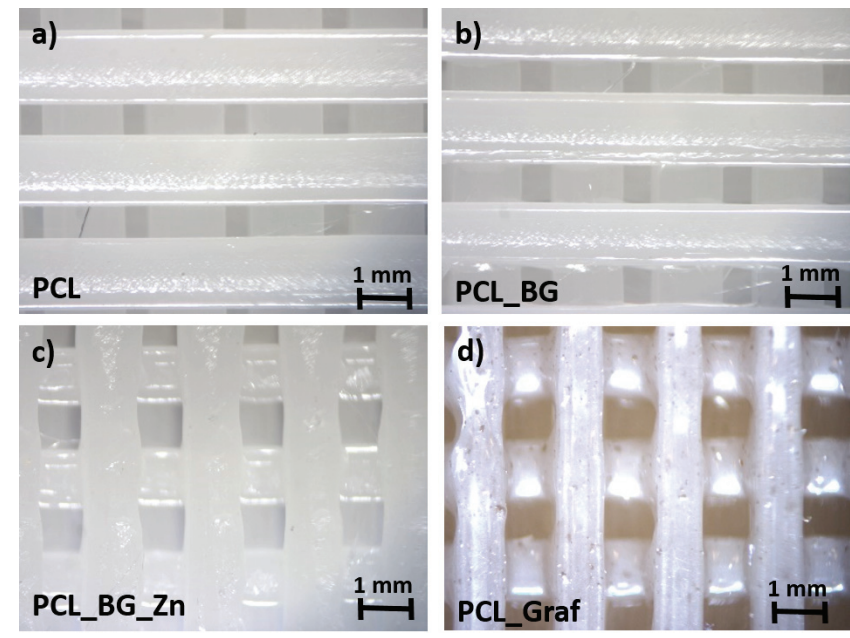

Fig. 2. Microscopic images of prepared biomaterials:

(a) Pure PCL sample, (b) PCL modified with bioglass,

(c) PCL modified with Zink doped bioglass,

(d) PCL modified with $5 \%$ of GNP

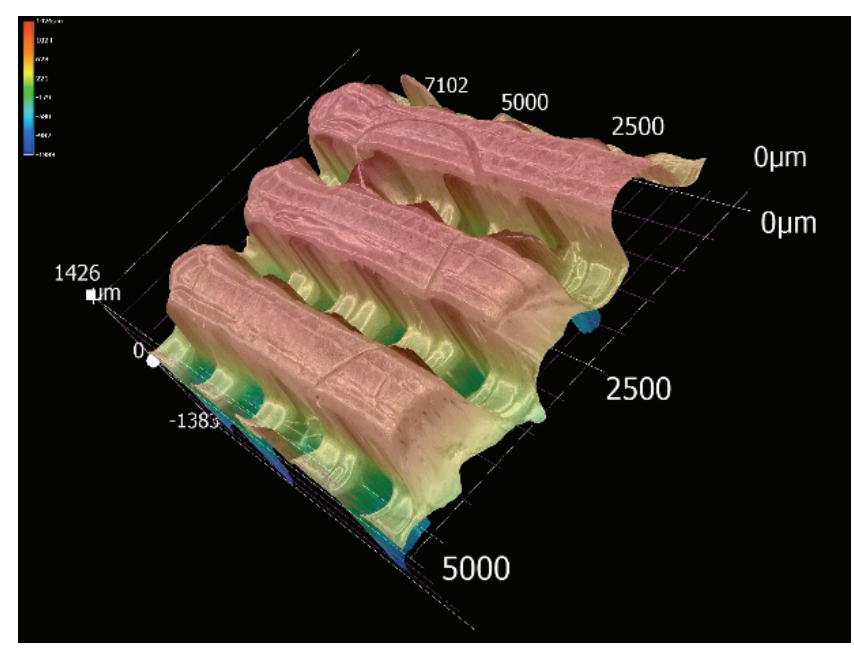

Fig. 3. Macroscopic evaluation of the surface - pure PCL

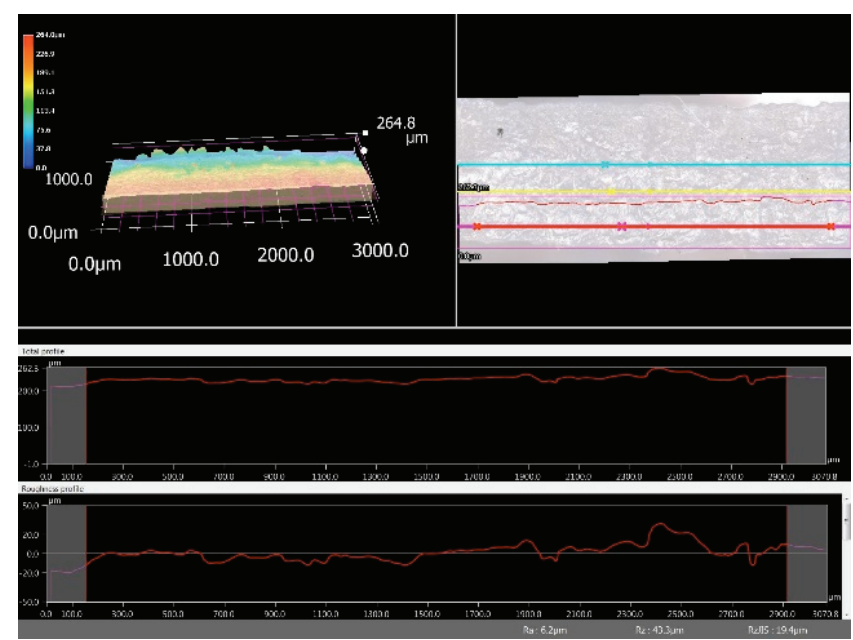

Fig. 4. Surface profile

- PCL $+0.4 \%$ biomaterials Bioglass

\subsection{Bacteriological analysis}

The aim of the microbiological tests was to assess the antimicrobial effect of the four biomaterials tested against the selected three reference microbial strains: Staphylococcus aureus ATCC 25293, Escherichia coli ATCC 25922, Candida albicans ATCC 10231.

Microbiological tests in vitro used the following culture media and reagents:

- Columbia agar (bioMerieux, Marcy l'Etoile, France), - Mac Conkey agar (bioMerieux, Marcy l'Etoile, France),

- Sabouraud agar (bioMerieux. Marcy l'Etoile, France), thinners: tryptone water, $\mathrm{NaCl}$ solution $(0.85 \%)$.

All stages of microbiological tests were carried out in accordance with the principles of asepsis and antiseptics. Each biomaterial was tested in four replicates with each of the reference microbial strains. A single sample of the tested biomaterial was placed in $2 \mathrm{ml}$ of the reference strain suspension with a final density of $1.5 \times 10^{5} \mathrm{CFU} / \mathrm{ml}$ in tryptone water (CFU - colony forming unit, i.e., a single colony forming unit, that is a single microorganism cell). The positive control was a suspension of $2 \mathrm{ml}$ volume of a given reference strain of a microorganism in tryptone water, while the negative control $2 \mathrm{ml}$ of tryptone water. After 17 hours of incubation in dynamic conditions (ThermShaker PST-60HL-4 from BioSan, Riga, Latvia) at $37{ }^{\circ} \mathrm{C}$ (S. aureus and E. coli) or $35{ }^{\circ} \mathrm{C}$ (C. albicans) (Fig. 6) from each test and control sample, $20 \mu \mathrm{L}$ of suspension was inoculated onto a solid microbial culture medium: Columbia agar with $5 \%$ sheep blood (S. aureus) (Fig. 7), MacConkey agar (E. coli) (Fig. 8) or Sabouraud agar (C. albicans) (Fig. 5). 
After 24 hours of incubation at $37{ }^{\circ} \mathrm{C}(S$. aureus and E. coli) or 48 hours of incubation at $35^{\circ} \mathrm{C}$ (C. albicans), the microbial colonies observed were counted using an automatic colony counting device "aCOLyte" (Symbios, Cambridge, UK) in order to determine the $\mathrm{ABE}$ (antibacterial efficacy) and the AFE (antifungal efficacy) of the materials under study. ABE and AFE were calculated with the use of the following formula [27]:

$\mathrm{ABE}[\%]$ or $\mathrm{AFE}[\%]=\frac{V c-V t}{V c} \times 100$,

$V c$ - number of microbial colonies cultured for positive control,

$V t$ - number of microbial colonies cultured for a given test sample.

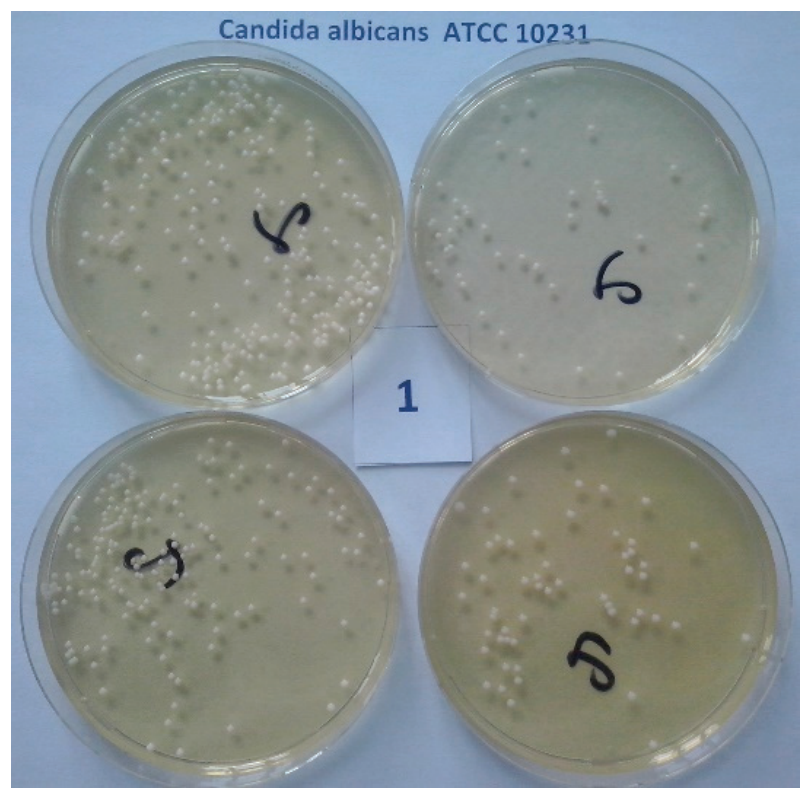

Fig. 5. Cultivation of C. albicans

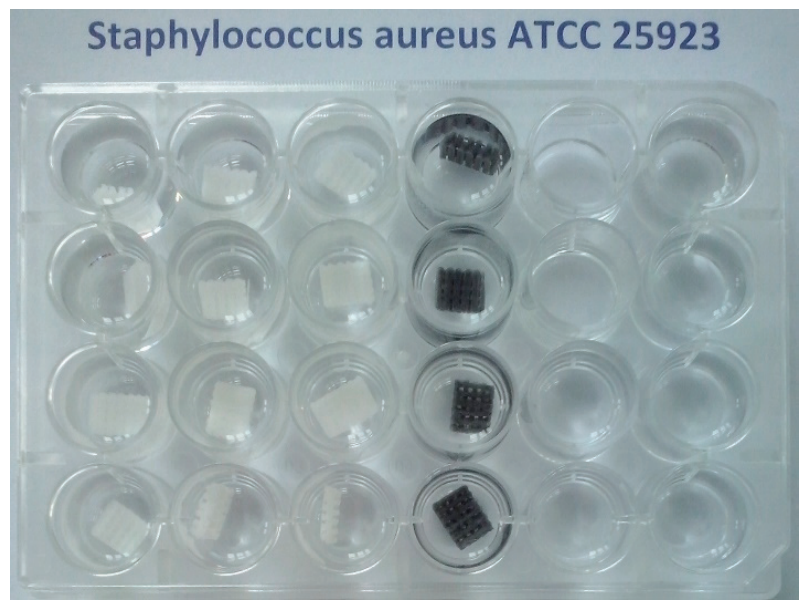

Fig. 6. PCL, PCL_BG, PCL_BG_Zn, PCL_GNP_5\% biomaterials in $S$. aureus solution

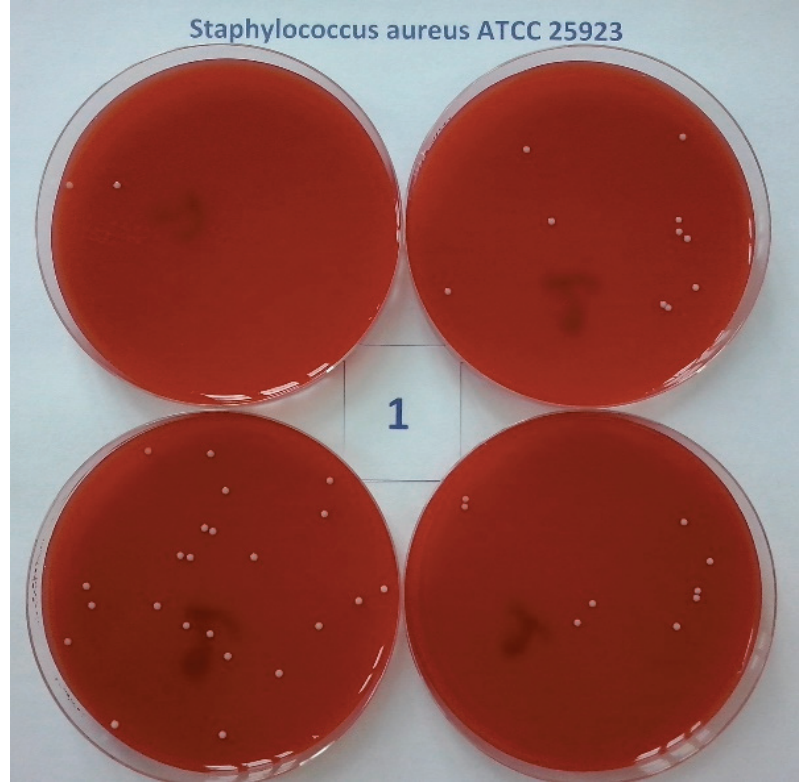

Fig. 7. Cultivation of S. aureus

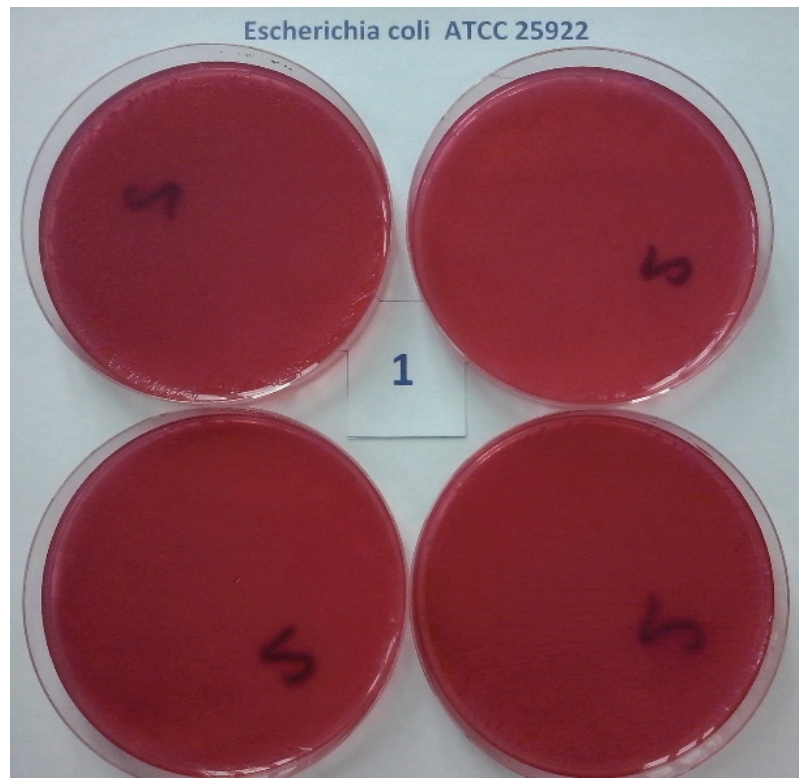

Fig. 8. Cultivation of E. coli

\section{Results}

Negative controls - normal (no microbial growth). Positive controls - normal (growth of colonies from the reference microbial strains). The number of observed microorganisms expressed in the form of the CFU number after 17 hours of incubation and the resulting antibacterial efficacy (ABE) are both presented in Table 2. 
Table 2. Overview of the number of microorganisms in individual preparations [CFU] and antibacterial efficacy $[\mathrm{ABE}]$ for a given samples

\begin{tabular}{|c|c|c|c|c|c|c|}
\hline \multirow[b]{2}{*}{$\begin{array}{l}\text { Preparation } \\
\text { tested }\end{array}$} & \multicolumn{2}{|c|}{$\begin{array}{l}\text { Staphylococcus aureus ATTC } 25923 \\
- \text { initial density } 1.5 \times 10^{5} \mathrm{CFU} / \mathrm{ml}\end{array}$} & \multicolumn{2}{|c|}{$\begin{array}{c}\text { Escherichia coli ATTC } 25922 \\
\text { - initial density } 1.5 \times 10^{5} \mathrm{CFU} / \mathrm{ml}\end{array}$} & \multicolumn{2}{|c|}{$\begin{array}{c}\text { Candida albicans ATTC } 10231 \\
- \text { initial density } 1.5 \times 10^{5} \mathrm{CFU} / \mathrm{ml}\end{array}$} \\
\hline & $\begin{array}{c}\text { The number } \\
\text { of CFU/ml after } \\
17 \text { hours of } \\
\text { incubation with } \\
\text { the preparation in } \\
\text { individual samples }\end{array}$ & $\begin{array}{c}\text { Antibacterial } \\
\text { efficacy (ABE) } \\
{[\%] \text { in individual }} \\
\text { samples }\end{array}$ & $\begin{array}{l}\text { The number } \\
\text { of CFU/ml after } \\
17 \text { hours of } \\
\text { incubation with } \\
\text { the preparation in } \\
\text { individual samples }\end{array}$ & $\begin{array}{c}\text { Antibacterial } \\
\text { efficacy (ABE) } \\
{[\%] \text { in individual }} \\
\text { samples }\end{array}$ & $\begin{array}{c}\text { The number } \\
\text { of CFU/ml after } \\
17 \text { hours of } \\
\text { incubation with } \\
\text { the preparation in } \\
\text { individual samples }\end{array}$ & $\begin{array}{c}\text { Antibacterial } \\
\text { efficacy (ABE) } \\
{[\%] \text { in individual }} \\
\text { samples }\end{array}$ \\
\hline PCL & \begin{tabular}{|c|}
32 \\
4 \\
19 \\
158 \\
\end{tabular} & $\begin{array}{c}9.57 \\
26.64 \\
28.93 \\
57.43 \\
\end{array}$ & $\begin{array}{c}2.1 \times 10^{8} \\
- \text { confluent growth } \\
\text { obtained for each } \\
\text { repeat test }\end{array}$ & $\begin{array}{l}0 \\
0 \\
0 \\
0\end{array}$ & \begin{tabular}{|l|}
10250 \\
13000 \\
13450 \\
13150 \\
\end{tabular} & $\begin{array}{l}63.8 \\
54.1 \\
52.6 \\
53.6 \\
\end{array}$ \\
\hline PCL_BGZn & $\begin{array}{c}2 \\
10 \\
23 \\
9\end{array}$ & $\begin{array}{l}99.99 \\
99.98 \\
99.96 \\
99.96\end{array}$ & $\begin{array}{c}2.1 \times 10^{8} \\
- \text { confluent growth } \\
\text { obtained for each } \\
\text { repeat test }\end{array}$ & $\begin{array}{l}0 \\
0 \\
0 \\
0\end{array}$ & $\begin{array}{c}8150 \\
3350 \\
3650 \\
10650\end{array}$ & $\begin{array}{l}71.2 \\
88.2 \\
86.1 \\
62.4\end{array}$ \\
\hline PCL_BG & $\begin{array}{l}4 \\
3 \\
3 \\
1\end{array}$ & $\begin{array}{l}99.99 \\
99.99 \\
99.99 \\
99.99\end{array}$ & $\begin{array}{c}2.1 \times 10^{8} \\
- \text { confluent growth } \\
\text { obtained for each } \\
\text { repeat test }\end{array}$ & $\begin{array}{l}0 \\
0 \\
0 \\
0\end{array}$ & $\begin{array}{l}8600 \\
6500 \\
9850 \\
8850\end{array}$ & $\begin{array}{l}69.7 \\
77.1 \\
65.2 \\
68.8\end{array}$ \\
\hline PCL_GNP $0.5 \%$ & $\begin{array}{c}24 \\
19 \\
15 \\
8\end{array}$ & $\begin{array}{l}82.78 \\
88.50 \\
93.21 \\
98.71\end{array}$ & $\begin{array}{c}2.1 \times 10^{8} \\
- \text { confluent growth } \\
\text { obtained for each } \\
\text { repeat test }\end{array}$ & $\begin{array}{l}0 \\
0 \\
0 \\
0\end{array}$ & $\begin{array}{c}11550 \\
10150 \\
5500 \\
4300\end{array}$ & $\begin{array}{l}53.61 \\
59.24 \\
77.91 \\
82.73\end{array}$ \\
\hline PCL-GNP 5\% & $\begin{array}{c}7.0 \times 10^{4} \\
\text { - confluent growth } \\
\text { obtained for each } \\
\text { repeat test }\end{array}$ & $\begin{array}{l}0 \\
0 \\
0 \\
0\end{array}$ & $\begin{array}{c}2.1 \times 10^{8} \\
- \text { confluent growth } \\
\text { obtained for each } \\
\text { repeat test }\end{array}$ & $\begin{array}{l}0 \\
0 \\
0 \\
0\end{array}$ & $\begin{array}{l}33950 \\
40500 \\
16100 \\
25500\end{array}$ & $\begin{array}{c}0 \\
0 \\
43.2 \\
10\end{array}$ \\
\hline PCL-GNP 10\% & \begin{tabular}{|c|}
$7.0 \times 10^{4}$ \\
- confluent growth \\
obtained for each \\
repeat test \\
\end{tabular} & $\begin{array}{l}0 \\
0 \\
0 \\
0\end{array}$ & $\begin{array}{c}2.1 \times 10^{8} \\
- \text { confluent growth } \\
\text { obtained for each } \\
\text { repeat test }\end{array}$ & $\begin{array}{l}0 \\
0 \\
0 \\
0\end{array}$ & $\begin{array}{c}5.0 \times 10^{4} \\
\text { - confluent growth } \\
\text { obtained for each } \\
\text { repeat test }\end{array}$ & $\begin{array}{l}0 \\
0 \\
0 \\
0 \\
\end{array}$ \\
\hline
\end{tabular}

Fig. 9. Average ABE values for S. aureus

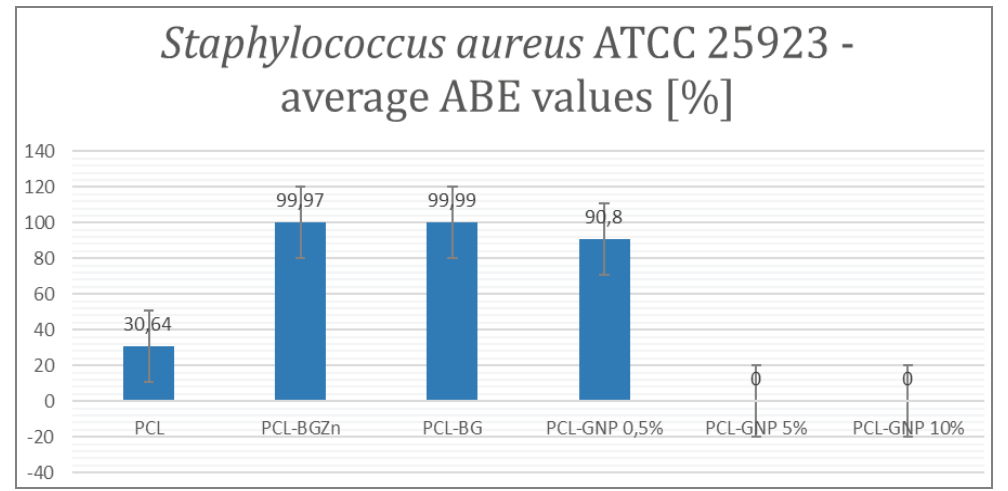

Fig. 10. Average ABE values for E. coli $(0 \%)$

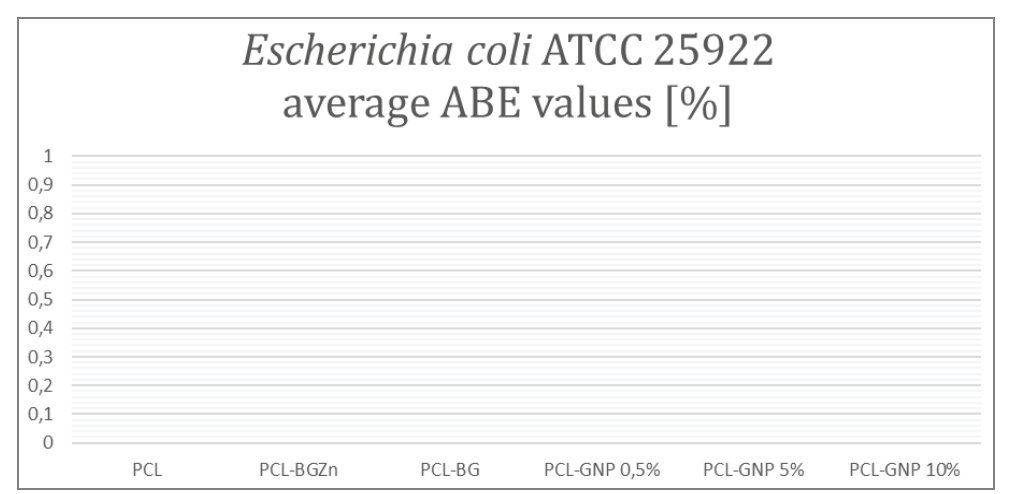




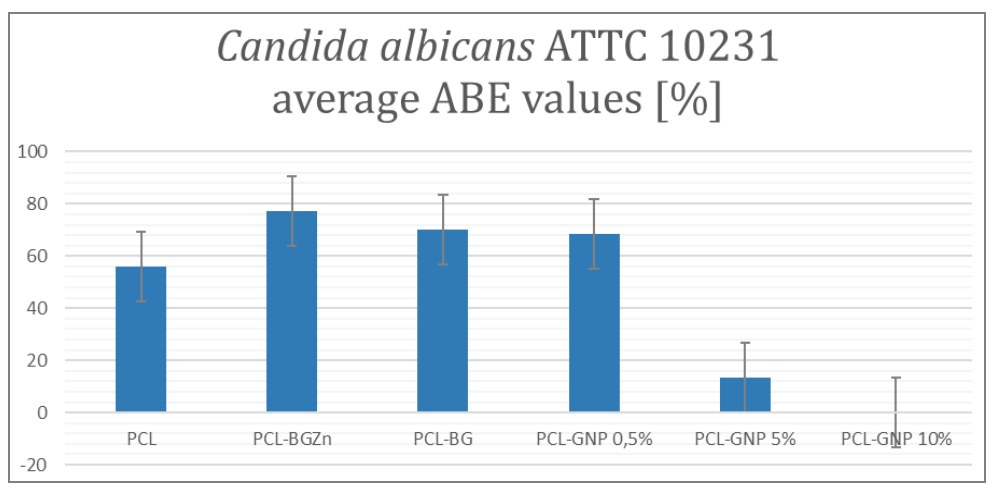

Fig. 11. Average ABE values for C. albicans
In charts presented in Figs. 9-11, the summary of the antibacterial efficacy in the form of average ABE values [\%] was presented.

\section{Discussion}

The research results point to a significant antibacterial efficacy of the tested materials against $S$. aureus and $C$. albicans, which, however, seems to decrease with increasing graphene content in the filaments. A complete lack of antibacterial efficacy against $E$. coli was determined.

In the case of $S$. aureus, pure PCL shows only slight antibacterial activity at the level of $30 \%$ ABE. Its modification with a small amount of bioglass $(0.4 \%$ wt. $)$ or zinc-doped bioglass results in a significant increase in antibacterial efficacy to more than 99\% ABE. Modification with a small amount of graphene $(0.5 \%)$ causes a significant increase in antibacterial efficacy, reaching the level of $90 \%$ ABE. Further increase of graphene content significantly reduces and inhibits the antibacterial properties of PCL. Several authors emphasise the relevant antibacterial properties of graphene, but in the form of its oxides [14], [17]. The structure of graphene may cause damage to the cell membranes of microbes and thus eliminate them. During filament preparation, polymer granules were dry-mixed together with GNP powder. In all likelihood, the carbon particles that precipitated while preparing the suspension for the culture became the feed for the cultured bacteria. Nevertheless, it may be concluded that the addition of only a small amount of graphene to PCL filaments $(0.5 \%)$ leads to a significant increase in its antibacterial efficacy, compared to pure PCL, while further increase of graphene content effectively reduces the antibacterial efficacy in such filaments.

None of the tested filaments showed any activity against $E$. coli. In all cases, the inoculated suspension caused a confluent growth of these bacteria. However, many researchers confirm that PCL shows activity against $E$. coli, but only if the polymer is modified, for example, with silver nanoparticles. It has been confirmed that zinc oxide exhibits activity against $E$. coli [15]. Adding a small amount of bioglass, as well as zinc-doped bioglass to the polymer did not lead to a significant increase in antibacterial properties either. This fact has been confirmed by the observations of those authors who claim not to have perceived any activity of bioglass against gram-negative bacteria [8]. The addition of silver ions enhances the antibacterial activity of bioglass [2].

Most of the tested materials, with the exception of PCL-GNP 5\% and PCL-GNP 10\%, exhibited significant antibacterial efficacy against $C$. albicans. In the case of PCL, the average ABE was approximately $55 \%$. The addition of bioglass to PCL increased this value to $70 \%$ and the doping bioglass with zinc - to almost $80 \%$. The $0.5 \%$ GNP admixture also caused a significant increase in the antibacterial efficacy to about $70 \%$, similarly as in the case of bioglass. The increase of graphene content in the filaments resulted in an effective reduction of the antibacterial properties of the biomaterials. It appears that it may have been caused by the process similar as in the case of $S$. aureus, whereby the carbon particles present in the suspension could become a feed for the bacteria. This is probably due to the process of carbon particles being released into the bacterial culture solution, which then wipes out the medium. The types of these mechanisms are discussed in detail in other work [29].

\section{Conclusions}

The use of the PCL polymer is common in modern medicine. Its appropriate modifications enhance its basic properties, in this case - antibacterial efficacy. The addition of small amounts of bioglass, zinc-doped 
bioglass or graphene significantly enhance this property.

The selected bacteria constitute a saprophytic flora in humans, however, in many cases they may cause serious infections, frequently suffered by people with weakened immune systems or undergoing immunosuppressive therapy. The tested biomaterials can be successfully used in implantology, where a need to create temporary tissue scaffolds occurs. It is especially important in the cases marked by an increased risk of a perioperative infection, for instance in otolaryngology, during intra-nasal surgeries.

\section{Acknowledgements}

This work was supported by the National Science Centre, Poland in the frame of project: "Layered scaffolds for nasal cartilages reconstruction fabricated by 3D printing and electrospinning" 2015/18/E/ST5/00189 (Sonata Bis 5) and by The National Centre for Research and Development in the frame of project: "Layered implants for nasal cartilages and bones reconstruction fabricated by 3D printing” TANGO-IV-A/0002/2019.

\section{References}

[1] Chen H., Gao D., Wang B., Zhao R., Guan M., Zheng L., Zhou X., Chai Z., FenG W., Graphene oxide as an anaerobic membrane scaffold and antagonistic effects against pathogenic E. coli and S. aureus, Nanotechnology, 2014, 25 (16), DOI: 10.1088/0957-4484/25/16/165101.

[2] CioŁek L., Karaś J., Olszyna A.R., ZaczyŃSKa E., CZarny A., Żywicka B., SzamaleK K., In Vitro Studies of Antibacterial Activity of Bioglasses Releasing $\mathrm{Ag}^{+}$, Key Eng. Mater., 2011, 493-494, 108-113, DOI: 10.4028/www.scientific.net/kem.493494.108.

[3] Dias A.M., Da Silva F.G., Monteiro A.P.F., PinzÓn-García A.D., Sinisterra R.D., Cortés M.E., Polycaprolactone nanofibers loaded oxytetracycline hydrochloride and zinc oxide for treatment of periodontal disease, Mater Sci. Eng. C. Mater., Biol. Appl., 2019, 103, 109798, DOI: 10.1016/ j.msec.2019.109798.

[4] DZiadek M., ZagrajcZuK B., MenasZek E., Wegrzynowicz A., Pawlik J., Cholewa-Kowalska K., Gel-derived $\mathrm{SiO}_{2}-\mathrm{CaO}-$ $\mathrm{P}_{2} \mathrm{O}_{5}$ bioactive glasses and glass-ceramics modified by $\mathrm{SrO}$ addition, Ceram. Int., 2016, 42 (5), 58, 42-57, DOI: 10.1016/ j.ceramint.2015.12.128.

[5] Fonseca G.F.D., Avelino S.D.O.M., Mello D.D.C.R., Prado R.F.D., Campos T.M.B., Vasconcellos L.M.R.D., TRICHES E.D.S., BorgeS A.L.S., Scaffolds of PCL combined to bioglass: synthesis, characterization and biological performance, J. Mater. Sci. Mater. Med., 2020, 31 (41), DOI: 10.1007/ s10856-020-06382-w.

[6] Fredenberg S., Wahlgren M., Reslow M., Axelsson A., The mechanisms of drug release in poly(lactic-co-glycolic acid)-based drug delivery systems - A review, Int. J. Pharm., 2011, 415 (1-2), 34-52, https://doi.org/10.1016/ j.ijpharm.2011.05.049.
[7] Han J.K., Marple B.F., Smith T.L., MurR A.H., Lanier B.J., Stambaugh J.W., MugGlin A.S., Effect of steroid-releasing sinus implants on postoperative medical and surgical interventions: an efficacy meta-analysis, Int. Forum Allergy and Rh., 2012 (2), 271-279, DOI: 10.1002/alr.21044.

[8] Hu S., Chang J., Liu M., Ning C., Study on antibacterial effect of 45S5 Bioglass $^{\circledR}$, J. Mater Sci. Mater Med., 2009, 20, 281-286, DOI: 10.1007/s10856-008-3564-5.

[9] JI H., Sun H., QU X., Antibacterial applications of graphene-based nanomaterials: Recent achievements and challenges, Adv. Drug. Deliv. Rev., 2016, 105 (Pt B), 176-189, DOI:10.1016/j.addr.2016.04.009.

[10] Karatas A., Pehlivanoglu F., Salviz M., Kuvat N., CEBI I.T., Dikmen B., SENGOZ G., The effects of the time of intranasal splinting on bacterial colonization, postoperative complications, and patient discomfort after septoplasty operations, Braz. J. Otorhinolar., 2016, 82 (6), 654-661, DOI:10.1016/j.bjorl.2015.11.008.

[11] Kurantowicz N., Sawosz E., Jaworski S., Kutwin M., Strojny B., Wierzbicki M., Szeliga J., Hotowy A., LiPIŃSKA L., KozIŃSKi R., JAGIEŁŁo J., ChWALIBOG A., Interaction of graphene family materials with Listeria monocytogenes and Salmonella enterica, Nanoscale Res. Lett., 2015, 10 (23), DOI: 10.1186/s11671-015-0749-y.

[12] Lina G., Boutite F., Tristan A., Bes M., Etienne J., VANDENESCH F., Bacterial Competition for Human Nasal Cavity Colonization: Role of Staphylococcal agr Alleles, Appl. Environ. Microb., 2003, 69 (1), 18-23, DOI: 10.1128/ AEM.69.1.18-23.200.

[13] Liu D., Nie W., Li D., Wang W., Zheng L., Zhang J., Zhang J., Peng C., Mo X., He C., $3 D$ printed PCL/SrHA scaffold for enhanced bone regeneration, Chem. Eng. J., 2019, 362 (15), 269-279, DOI:10.1016/j.cej.2019.01.015.

[14] Liu S., Zeng T.H., Hofmann M., Burcombe E., Wei J., JiAng R., Kong J., CHEN Y., Antibacterial activity of graphite, graphite oxide, graphene oxide, and reduced graphene oxide: membrane and oxidative stress, ACS Nano, 2011, 5 (9), 6971-6980.

[15] Liu Y., He L., Mustapha A., Li H., Hu Z., Lin M., Antibacterial activities of zinc oxide nanoparticles against Escherichia coli O157:H7, J. Appl. Microbiol., 2009, 107, 1193-1201, DOI: 10.1111/j.1365-2672.2009.04303.x.

[16] Ma J., Zhang J., Xiong Z., Yong Y., Zhao X.S., Preparation, characterization and antibacterial properties of silver-modified graphene oxide, J. Mater Chem., 2011, 21, 3350-3352.

[17] Mangadlao J.D., Santos C.M., Felipe M.J.L., LeOn A.C.C., Rodrigues D.F., Advincula R.C., On the antibacterial mechanism of graphene oxide (GO) Langmuir-Blodgett films, Chem. Commun., 2015, 51 (14), 2886-2889.

[18] Miola M., Verné E., Vitale-Brovarone C., Baino F, Antibacterial Bioglass-Derived Scaffolds: Innovative Synthesis Approach and Characterization, Int. J. Appl. Glass Sci., 2016, 7, 238-247, DOI:10.1111/ijag.12209.

[19] RajZer I., Kurowska A., JabŁoński A., KwiatKowski R., Piekarczyk W, Hajduga M.B., Kopeć J., Sidzina M., MENASZEK E., Scaffolds modified with graphene as future implants for nasal cartilage, J. Mater. Sci., 2020, 55 (9), 4030-4042.

[20] Rajzer I., DZiadek M., Kurowska A., Cholewa-Kowalska K., ZiąBKa M., Menaszek E., Douglas T.E.L., Electrospun polycaprolactone membranes with Zn-doped bioglass for nasal tissues treatment, J. Mater. Sci. Mater. Med, 2019, 30 (7), 80, DOI: 10.1007/s10856-019-6280-4. 
[21] Rapacz-Kmita A., Szaraniec B., MikolajczyK M., Stodolak-Zych E., Dzierzkowska E., GajeK M., Dudek P., Multifunctional biodegradable polymer/clay nanocomposites with antibacterial properties in drug delivery systems, Acta Bioeng. Biomech., 2020, 22 (2), DOI: 10.37190/ ABB-01523-2019-03

[22] Rohr N., Nebe J.B., Schmidli F., Müller P., Weber M., FISCHER H., FISCHER J., Influence of bioactive glass-coating of zirconia implant surfaces on human osteoblast behavior in vitro, Dent. Mater., 2019, 35 (6), 862-870, DOI:10.1016/ j.dental.2019.02.029.

[23] SZPONDER T., Stodolak-ZyCH E., POlkowSKA I., SOBCZYŃSKA-RAK A., Impact of a pulsed magnetic field on selected polymer implant materials, Acta Bioeng. Biomech., 2019, 21 (1), DOI: 10.5277/ABB-01253-2018-04.

[24] Turek A., Stoklosa K., Borecka A., Paul-Samojedny M., KaczmarczyK B., Marcinkowski A., KasperczyK J., Designing Biodegradable Wafers Based on Poly(L-lactide-coglycolide) and Poly(glycolide-co-£-caprolactone) for the Prolonged and Local Release of Idarubicin for the Therapy of Glioblastoma Multiforme, Pharm. Res., 2020, 37 (5), 90, DOI: 10.1007/s11095-020-02810-2.
[25] Woodruff M.A., Hutmacher D.W., The return of a forgotten polymer - Polycaprolactone in the 21st century, Prog. Polym. Sci., 2010, 35 (10), 1217-1256.

[26] Wu F., Wei J., Liu C., O’Neill B., Ngothai Y., Fabrication and properties of porous scaffold of zein/PCL biocomposite for bone tissue engineering, Compos. Part B-Eng., 2012, 43 (5), 2192-2197.

[27] XiaOYi X., Qingbiao Y., Yongzhi W., Haijun Y., Xuesi C., XIABIN J., Biodegradable electrospun poly(l-lactide) fibers containing antibacterial silver nanoparticles, Eur. Polym. J., 2016, 42 (9), 2081-2087, DOI:10.1016/j.eurpolymj.2006.03.032.

[28] Zanni E., Bruni E., Chandraiahgari C.R., De Bellis,G., Santangelo M.G., Leone M., Bregnocchi A., Mancini P., SARTO M.S., UCCELLETTI D., Evaluation of the antibacterial power and biocompatibility of zinc oxide nanorods decorated graphene nanoplatelets: new perspectives for antibiodeteriorative approaches, J. Nanobiotechnol., 2017, 15, 57, DOI: 10.1186/s12951-017-0291-4.

[29] Zhan S., Zhu D., Ma S., Yu W., Jia Y., Li Y., Yu H., SHEN Z., Highly efficient removal of pathogenic bacteria with magnetic graphene composite, ACS Appl. Mater Interfaces, 2015, 7 (7), 4290-4298. 